\title{
Ethnic sensitivity assessment of fluticasone furoate/vilanterol in East Asian asthma patients from randomized double-blind multicentre Phase IIb/III trials
}

Annette S. Gross ${ }^{1 *}$, Caroline Goldfrad ${ }^{2}$, Soichiro Hozawa ${ }^{3}$, Mark H. James ${ }^{4}$, Christine S. Clifton ${ }^{1}$, Yutaro Sugiyama ${ }^{5}$ and Loretta Jacques ${ }^{6}$

\begin{abstract}
Background: Fluticasone furoate (FF)/vilanterol (VI) is a once daily (OD) inhaled corticosteroid/long-acting $\beta_{2}$-agonist combination asthma therapy approved in Japan and the EU. FF/NI efficacy and safety data from asthma studies including patients in East Asia were evaluated to assess ethnic sensitivity.

Methods: Randomized, double-blind, multicenter Phase IIb/III trials were assessed. Change from baseline relative to placebo or twice-daily fluticasone propionate $500 \mu \mathrm{g}$ in trough $\mathrm{FEV}_{1}$ was compared between patients from Japan $(N=148)$ and Not-Japan ( $N=3,066$; three studies). Adverse events (AEs), laboratory results, and electrocardiograms were compared between patients from Japan + Korea $(N=188)$ and Not-Japan + Korea ( $N=3,840$; five studies).

Results: For trough FEV 1 , improvements from baseline (least-squares mean difference [95 \% confidence interval]) were reported for FF/NI 100/25 $\mu \mathrm{g}$ OD versus placebo at Week 12 (Japan: 0.323 L [0.104-0.542]; Not-Japan: $0.168 \mathrm{~L}$ [0.095-0.241]). Improvements from baseline (least-squares mean change [standard error]) were reported with FF/NI 200/25 $\mu \mathrm{g}$ OD at Week 24 (Japan: 0.355 L [0.1152]; Not-Japan: 0.396 L [0.0313]). A greater proportion of patients from Japan + Korea versus Not-Japan + Korea reported AEs in all treatment arms including placebo (FFNI 100/25 $\mu g$ :

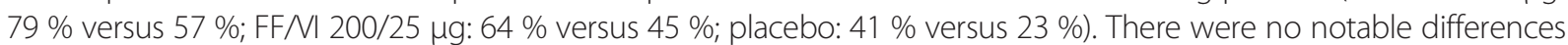
in treatment-related or class-related AEs. No clinically significant changes in electrocardiogram assessments or statistically significant differences in $24 \mathrm{~h}$ urinary cortisol excretion were observed between the Japan + Korea and Not-Japan + Korea cohorts.
\end{abstract}

Conclusions: Good efficacy and an acceptable safety profile were observed for FF/NI 100/25 $\mu \mathrm{g}$ and 200/ $25 \mathrm{\mu g} \mathrm{OD}$ in East Asian asthma patients; these globally recommended doses are appropriate for asthma patients in Japan.

Trial registration: Clinicaltrials.gov registration numbers: NCT01165138, NCT01134042, NCT01086384, NCT00603278, NCT00603382.

Keywords: $\beta_{2}$-adrenergic receptor agonists, Asthma, Glucocorticoids, Japan, Treatment outcome

\footnotetext{
* Correspondence: annette.s.gross@gsk.com

${ }^{1}$ Clinical Pharmacology Modelling \& Simulation, GSK R\&D, 82 Hughes Ave,

Ermington, Sydney NSW 2115, Australia

Full list of author information is available at the end of the article
} 


\section{Background}

Asthma represents a considerable disease burden worldwide. The prevalence of asthma in Japan is amongst the highest in Asia [1]. Japanese [2] and global asthma guidelines [3] recommend the use of a low-dose inhaled corticosteroid (ICS) and long-acting $\beta_{2}$-agonist (LABA) combination as step-up therapy for asthma patients uncontrolled using reliever medication and low-dose ICS alone. The inhaled ICS and LABA combination of fluticasone furoate (FF) and vilanterol (VI) is suitable for oncedaily (OD) dosing having $24 \mathrm{~h}$ efficacy in asthma patients $[4,5]$. FF/VI is delivered via the ELLIPTA ${ }^{\oplus}$ dry powder inhaler (DPI; ELLIPTA ${ }^{\circ}$ is a trademark of the GSK group of companies).

The Japanese and global asthma guidelines support the use of ICS/LABA combination inhalers $[2,3]$; they reduce the number of inhalation procedures, increase patient adherence, and reduce the risk of the LABA being delivered alone [2]. Additionally, OD therapy has been shown to improve treatment adherence in asthma patients $[6,7]$ and is associated with treatment success and decreased healthcare costs [8]. OD FF/VI 100/25 $\mu \mathrm{g}$ and 200/25 $\mu \mathrm{g}$ are approved in Japan, the USA, and the European Union for the treatment of asthma.

The multiregional global development program of FF/VI included patients from a range of ethnic groups, including East Asian patients from Japan and Korea. Based on the totality of data from the global development program, the $100 / 25 \mu \mathrm{g}$ and $200 / 25 \mu \mathrm{g}$ strengths of FF/VI were recommended for the treatment of asthma. As responses to pharmacotherapy can vary across ethnic groups $[9,10]$, the potential ethnic sensitivity of FF/VI efficacy and safety in East Asian patients was assessed, using data from the studies that included asthma patients in Japan and Korea. This analysis also supported the asthma FF/VI submission for regulatory approval in Japan. Consequently, the focus of this assessment is asthma patients in Japan and therefore, efficacy data from patients in Japan have been compared with data from patients in all countries other than Japan. This comparison is important to determine whether the results in the subjects in Japan are comparable with all other subjects studied and, therefore, whether there is a major difference in drug response in patients in Japan relative to all other subjects studied. To provide more reliable conclusions on the safety profile of FF/VI in East Asian asthma patients, safety data from patients in Korea were included to increase the number of patients in the safety assessment. The safety results of asthma patients from Japan and/or Japan + Korea versus Not-Japan and/ or NotJapan + Korea have therefore been compared.

\section{Methods}

This was a pre-specified efficacy and safety subgroup analysis of all multicenter, randomized, double-blind, parallel-group, multiregional studies that included East Asian asthma patients recruited in Japan (three Phase III studies: efficacy assessment) and Japan and/or Korea (five studies: safety assessment). Inclusion and exclusion criteria are presented in each clinical trial summary (Clinicaltrials.gov; registration numbers: NCT01165138, NCT01134042, NCT01086384, NCT00603278 and NCT00603382) and asthma-related clinical criteria are described in Additional Files 1 and 2. In brief, nonsmoking patients with a diagnosis of asthma as defined by the National Institutes of Health [11] aged $\geq 12$ years with a pre-bronchodilator $\%$ predicted forced expiratory volume in one second $\left(\mathrm{FEV}_{1}\right)$ of $40-90 \%$, and $\mathrm{FEV}_{1}$ reversibility of $\geq 12 \%$ and $\geq 200 \mathrm{~mL}$ within $10-40 \mathrm{~min}$ following 200-400 $\mu \mathrm{g}$ inhaled salbutamol were included. Permitted baseline asthma therapies are described in Additional Files 1 and 2. All studies included in the analysis were approved by local ethics committees (Additional File 3) and carried out in accordance with the Declaration of Helsinki [12]. All patients provided written informed consent prior to undertaking any study-related procedures.

\section{Efficacy analysis}

Efficacy data are presented from three Phase III studies that included asthma patients in Japan: HZA106827 (Clinicaltrials.gov registration number NCT01165138) [4]; HZA106829 (NCT01134042) [5]; HZA106837 (NCT01086384) [13] (Additional File 1). FF/VI 100/ $25 \mu \mathrm{g}$ OD and FF $100 \mu \mathrm{g}$ OD were investigated in studies HZA106827 (placebo-controlled) and HZA106837. FF/VI 200/25 $\mu \mathrm{g}$ OD, FF $200 \mu \mathrm{g}$ OD, and fluticasone propionate (FP) $500 \mu \mathrm{g}$ twice daily (BD) were investigated in study HZA106829. FF/VI and placebo were delivered via the ELLIPTA DPI and FP was delivered via the DISKUS ${ }^{\oplus}$ (DISKUS ${ }^{\oplus}$ is a trademark of the GSK group of companies) DPI. A range of efficacy endpoints were assessed in the individual studies, but only trough $\mathrm{FEV}_{1}$ measured at the end of a dosing interval (the primary endpoint in studies HZA106827 and HZA106829 and a secondary endpoint in study HZA106837) was analyzed in the Japan subgroup, as pre-specified in the analysis plan. Efficacy data were analyzed for patients recruited from Japan (Japan cohort), all patients that were not recruited from Japan (Not-Japan cohort), and all patients studied (Overall population). Patients were assigned to these cohorts according to the country in which they were recruited and not according to race. Ease of use of the ELLIPTA inhaler was also assessed by questionnaire in study HZA106827.

Change from baseline in trough $\mathrm{FEV}_{1}$ at Week 12 was pooled for each treatment arm from studies HZA106827 and HZA106837. Statistical analyses for treatment comparisons at Week 12 were conducted for FF/VI 100/25 $\mu \mathrm{g}$ 
versus placebo, FF/VI 100/25 $\mu \mathrm{g}$ versus FF $100 \mu \mathrm{g}$, and FF $100 \mu \mathrm{g}$ versus placebo. In the individual studies included in this analysis, sensitivity analyses (using repeated measures analyses) supported the primary analysis using last observation carried forward (LOCF) data for imputation of missing data. Consequently, LOCF data were used to perform the current statistical analysis using an analysis of covariance (ANCOVA) model. Effects due to geographic region, baseline $\mathrm{FEV}_{1}$, gender, age, treatment group, and study were modeled. An interaction term for treatment by geographic region (Japan/Not-Japan) was also included in the model. A similar modeling process was used to analyze the results of the FP $500 \mu \mathrm{g}$ BD-controlled study HZA106829, in which FF/VI 200/25 $\mu \mathrm{g}$ and FF $200 \mu \mathrm{g}$ were assessed at Weeks 12 (post-hoc analysis) and 24, using last observation carried forward data.

Withdrawals due to lack of efficacy were summarized for each cohort in the efficacy dataset.

\section{Safety analysis}

Safety data were pooled from five clinical studies: the three studies included in the efficacy assessment and an additional two placebo-controlled FF Phase IIb studies that included East Asian patients in Korea: FFA109685 (NCT00603278) [14]; FFA109687 (NCT00603382) [15] (Additional File 2). These two studies were included in the integrated safety analysis to increase the number of East Asian patients assessed and thereby increase confidence in the results. There are similarities in intrinsic and extrinsic ethnic factors in the populations of Japan and Korea [16-18], supporting the pooling of patient results in these two East Asian populations, which has increased the number of East Asian patients assessed and thereby increased confidence in the conclusions that can be drawn.

All five studies assessed a comprehensive range of safety endpoints, which are presented in the relevant publications; however, for brevity we only assessed key safety data in the Japan subgroup, as pre-specified in the analysis plan. Safety data were compared between treatment arms for patients recruited from Japan and Korea (Japan + Korea cohort), patients recruited from all other countries (NotJapan + Korea cohort), and all patients studied (Overall population). The safety results are considered for OD

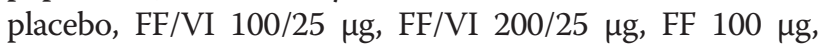
and FF $200 \mu \mathrm{g}$ from studies HZA106827, HZA106837, HZA106829, FFA109685, and FFA109687. Results for the doses of FF monotherapy that were not progressed to Phase III for FF/VI from these five studies are not presented. FP $100 \mu \mathrm{g}$ BD, FP $250 \mu \mathrm{g}$ BD, and FP $500 \mu \mathrm{g}$ BD were also included in the analysis of urinary cortisol data.

The incidence of all adverse events (AEs), treatmentrelated AEs, and serious AEs (SAEs), including exacerbations, was summarized for patients in Japan + Korea, Not-Japan + Korea, and the Overall population of the pooled data set. Electrocardiogram (ECG) results including QT corrected using Frederica's correction (QTcF) were also assessed in a subset of patients from HZA106827 and HZA106829. AEs related to known ICS or LABA class effects were a focus, including lower respiratory tract infections (bronchitis and pneumonia), cardiovascular effects (heart rate and ECG), and effects on glucose and potassium. An Asthma Composite Endpoint was also derived to assess independently adjudicated asthma-related hospitalizations, intubations, and deaths in studies HZA106837, HZA106827, and HZA106829.

The urinary cortisol excretion over $24 \mathrm{~h}$ was measured at baseline and at the end of the treatment period in a subset of patients from studies FFA109685, FFA109687, HZA106827, and HZA106829 (Urinary Cortisol population). For treatment comparisons, the urinary cortisol excretion ratio (end of treatment/baseline) was analyzed using an ANCOVA model of the log-transformed urinary cortisol excretion with effects due to geographic region, log baseline urinary cortisol, gender, age, treatment group, and study. For the analysis by geographic region and for estimation of regional treatment differences, an interaction term for treatment by geographic region (Japan + Korea/ Not-Japan + Korea) was also included in the model.

Withdrawals due to AEs were summarized for each cohort in the safety dataset.

\section{Results}

\section{Efficacy analysis}

The intent-to-treat populations in the three efficacy studies comprised 3,214 patients recruited in 11 countries (overall population); including 148 patients (5\%) recruited from Japan (Additional File 1). Eighty-five percent of patients in the Overall population and $70 \%$ of the Japan cohort completed the respective study. A higher proportion of patients recruited from Japan (14\%; $N=21 / 148)$ than Not-Japan ( $3 \% ; N=104 / 3,066)$ withdrew due to lack of efficacy. In the Japan cohort, a greater proportion of patients withdraw due to lack of efficacy with placebo (42\%) than with FF/VI (7-9 \%). A similar pattern was observed in the Not-Japan group (placebo $13 \%$, FF/VI 1-3\%).

Demographic and baseline characteristics for the Japan and Not-Japan patients are presented in Table 1. All patients recruited from Japan were of East Asian ancestry and patients from the Not-Japan cohort were principally White/Caucasian (81 \%), but included small proportions of patients of a range of geographic ancestries (Additional File 1). Mean baseline prebronchodilator $\mathrm{FEV}_{1}$ was lower in patients recruited from Japan than Not-Japan, consistent with the literature and the lower average height of the Japan patients $[19,20]$. Furthermore, patients recruited from 
Table 1 Patient demographics and lung function at screening and baseline (Efficacy population)

\begin{tabular}{|c|c|c|c|}
\hline & $\begin{array}{l}\text { Japan } \\
N=148\end{array}$ & $\begin{array}{l}\text { Not-Japan } \\
N=3,066\end{array}$ & $\begin{array}{l}\text { Overall } \\
N=3,214\end{array}$ \\
\hline \multicolumn{4}{|l|}{ Demographic characteristics } \\
\hline Age, years* & $47.5(14.66)$ & $41.9(16.63)$ & $42.2(16.59)$ \\
\hline Range: min, $\max$ & 20,82 & 12,84 & 12,84 \\
\hline Male/female, \% & $38 / 62$ & $36 / 64$ & $36 / 64$ \\
\hline Weight, kg* & $62.5(13.63)$ & $76.2(19.29)$ & 75.5 (19.28) \\
\hline Height, $\mathrm{cm}^{*}$ & $160.7(8.05)$ & $165.7(9.98)$ & $165.5(9.96)$ \\
\hline \multicolumn{4}{|c|}{ Screening and baseline lung function characteristics } \\
\hline \multicolumn{4}{|l|}{ Screening } \\
\hline Pre-bronchodilator FEV ${ }_{1}, L^{*}$ & $1.87(0.505)$ & $2.13^{\dagger}(0.619)$ & $2.12^{\ddagger}(0.617)$ \\
\hline$\%$ predicted pre-bronchodilator $\mathrm{FEV}_{1}, \% *$ & $72.63(10.715)$ & $67.39^{\dagger}(11.179)$ & $67.63^{\ddagger}(11.210)$ \\
\hline Post-bronchodilator FEV ${ }_{1}, L^{*}$ & $2.34(0.638)$ & $2.67^{\S}(0.768)$ & $2.65^{\natural}(0.766)$ \\
\hline Absolute reversibility in $\mathrm{FEV}_{1}, \mathrm{~mL}^{*}$ & $463.6(258.51)$ & $537.5^{\| \prime}(306.75)$ & $534.1^{* *}(305.05)$ \\
\hline Range: min,max & $197.0,2055.0$ & $6.0,2628.0$ & $6.0,2628.0$ \\
\hline $\mathrm{FEV}_{1}$ reversibility, \%* & $25.3(14.00)$ & $26.1^{\| \prime}(14.95)$ & $26.1^{* *}(14.90)$ \\
\hline Range: min, max & $12.0-129.9$ & $0.3-125.2$ & $0.3-129.9$ \\
\hline \multicolumn{4}{|l|}{ Baseline } \\
\hline Baseline FEV $1, L^{*}$ & $1.93^{\dagger \dagger}(0.548)$ & $2.23^{\ddagger \neq}(0.647)$ & $2.22^{\S \S}(0.646)$ \\
\hline$\%$ predicted ${ }^{\text {१ศ }}$ FEV $_{1}$ at baseline, \%* & $74.66^{+\dagger}(11.127)$ & $70.57^{\ddagger \neq}(11.182)$ & $70.75^{\S \S}(11.210)$ \\
\hline
\end{tabular}

$F E V_{1}$ forced expiratory volume in one second, min minimum, max maximum

Efficacy population consists of data from studies HZA106827, HZA106829, and HZA106837. ${ }^{*}$ Mean (SD); ${ }^{\dagger} N=3,055 ;{ }^{\ddagger} N=3,203 ;{ }^{5} N=3,063 ;{ }^{\mathrm{I}} N=3,211 ;$; $N=3,052$;

${ }^{* *} N=3,200 ;{ }^{+\dagger} N=147 ;{ }^{* \pm} N=3,059 ;{ }^{\S 5} N=3,206 ;{ }^{1 \uparrow}$ Study HZA106837 used the prediction equation of Hankinson et al. 1999 [34]; studies HZA106827 and HZA106829 used Hankinson et al. 2010 [35]

Japan had greater mean $\%$ predicted $\mathrm{FEV}_{1}$ values than the Not-Japan patients.

At Week 12, increases from baseline in trough $\mathrm{FEV}_{1}$ were observed for FF/VI 100/25 $\mu \mathrm{g}$, FF/VI 200/25 $\mu \mathrm{g}$, and all active treatments in the Japan and Not-Japan patients (Tables 2 and 3, and Fig. 1). The least-squares mean change from baseline in the placebo group showed a slight decrease in the Japan cohort $(-0.022 \mathrm{~L})$ compared with an increase in the Not-Japan cohort $(0.133 \mathrm{~L})$. Consequently, greater improvements from baseline for FF/VI 100/25 $\mu \mathrm{g}$ OD versus placebo were observed in patients recruited from Japan than Not-Japan, although the variability was greater in the Japan population due to the smaller number of subjects (Table 2). Adjusted treatment differences for FF/VI 100/25 $\mu \mathrm{g}$ versus placebo, FF $100 \mu \mathrm{g}$ versus placebo, and FF/VI 100/25 $\mu \mathrm{g}$ versus FF $100 \mu \mathrm{g}$ were directionally the same in the Japan and Not-Japan populations (Table 2, Additional File 4). Furthermore, there was no evidence of a statistically significant difference in trough $\mathrm{FEV}_{1}$ treatment effect between Japan and Not-Japan patients at Week $12(P=0.403)$.

In the separate FP $500 \mu \mathrm{g}$ BD-controlled study that assessed FF/VI 200/25 $\mu \mathrm{g}$ and FF $200 \mu \mathrm{g}$ at Weeks 12 and 24, the least-squares mean changes from baseline in trough $\mathrm{FEV}_{1}$ in all treatment arms were consistent in the Japan and Not-Japan patients (Table 3). The results in the Japan subset should be interpreted with caution due to the low number of patients in each treatment arm. Nevertheless in the Japan patients, the least-squares mean changes from baseline in trough $\mathrm{FEV}_{1}$ at Week 24 were numerically greater with OD FF/VI 200/25 $\mu \mathrm{g}$ $(0.355 \mathrm{~L})$ than with OD FF $200 \mu \mathrm{g}(0.086 \mathrm{~L})$, or BD FP $500 \mu \mathrm{g}(0.110 \mathrm{~L})$. This pattern was consistent with the results in the Not-Japan patients (FF/VI 200/25 $\mu \mathrm{g}$ : 0.396 L; FF $200 \mu \mathrm{g}$ : 0.206 L; FP $500 \mu \mathrm{g}$ : $0.191 \mathrm{~L}$ ).

In the Japanese asthma patients, the ELLIPTA DPI was considered easy or very easy to use by the majority of subjects (77\%), which is consistent with results for the Overall patient population (Additional Files 5 and 6).

\section{Safety analysis}

The safety analysis included 188 patients (5\%) recruited from Japan and Korea (Japan $N=148$, Korea $N=40$ ) included in the five studies (Overall Safety population $N=4,028$ recruited from 21 countries (Additional Files 1 and 2). Demographic and baseline characteristics of the Japan + Korea patients in the Safety population (data not shown) were consistent with the Efficacy population (Table 1). Studies were completed by $139(74 \%)$ patients in the Japan + Korea cohort and $3,266(85 \%)$ patients in the Not-Japan + Korea cohort. The number of patients who withdrew due to an AE 
Table 2 Treatment differences for change from baseline in trough $\mathrm{FEV}_{1}(\mathrm{~L})$ at Week 12 (Efficacy population)

\begin{tabular}{|c|c|c|c|c|}
\hline & & Placebo & FF/VI 100/25 $\mu \mathrm{g}$ OD & FF $100 \mu \mathrm{g} O D$ \\
\hline \multirow[t]{5}{*}{ Overall } & $\mathrm{N}$ & 203 & 1,210 & 1,215 \\
\hline & $\mathrm{n}^{\dagger}$ & 193 & 1,201 & 1,203 \\
\hline & LS mean change from baseline (SE) & $0.120(0.0333)$ & $0.301(0.0116)$ & $0.225(0.0116)$ \\
\hline & Difference vs placebo (95% Cl) & - & $0.181 *(0.111-0.252)$ & $0.105^{*}(0.034-0.175)$ \\
\hline & Difference vs FF 100 mg (95 \% Cl) & - & $0.077^{*}(0.045-0.108)$ & - \\
\hline \multirow[t]{5}{*}{ Japan } & N & 19 & 47 & 46 \\
\hline & $\mathrm{n}^{\dagger}$ & 18 & 46 & 46 \\
\hline & LS mean change from baseline (SE) & $-0.022(0.0955)$ & $0.301(0.0590)$ & $0.194(0.0591)$ \\
\hline & Difference vs placebo (95% Cl) & - & $0.323(0.104-0.542)$ & $0.216(-0.003-0.436)$ \\
\hline & Difference vs FF 100 mg (95 \% Cl) & - & $0.107(-0.056-0.270)$ & - \\
\hline \multirow[t]{5}{*}{ Not-Japan } & N & 184 & 1,163 & 1,169 \\
\hline & $\mathrm{n}^{\dagger}$ & 175 & 1,155 & 1,157 \\
\hline & LS mean change from baseline (SE) & $0.133(0.0345)$ & $0.301(0.0118)$ & $0.226(0.0118)$ \\
\hline & Difference vs placebo (95% Cl) & - & $0.168(0.095-0.241)$ & $0.093(0.020-0.166)$ \\
\hline & Difference vs FF 100 mg (95 \% Cl) & - & $0.075(0.043-0.108)$ & - \\
\hline
\end{tabular}

$C I$ confidence interval, FF fluticasone furoate, $L S$ least-squares, $O D$ once daily, $S E$ standard error, VI vilanterol

All values are in L. Data from studies HZA106827 and HZA106837. ${ }^{\dagger}$ Number of patients with analyzable data at Week $12 ;{ }^{*} P \leq 0.003 ;$ Overall: $\mathrm{FF} / \mathrm{VI} 100 / 25 \mu \mathrm{g} v$ placebo, FF100 $\mu \mathrm{g}$ vs placebo, FF/VI 100/25 $\mu \mathrm{g}$ vs FF100 $\mu \mathrm{g}$

Table 3 Treatment differences and change from baseline in trough FEV1 (HZA106829; Efficacy population)

\begin{tabular}{|c|c|c|c|c|c|c|c|}
\hline & & \multicolumn{2}{|l|}{$\mathrm{FP} 500 \mu \mathrm{g} \mathrm{BD}$} & \multicolumn{2}{|l|}{ FF/ 200/25 $\mu \mathrm{g}$ OD } & \multicolumn{2}{|l|}{ FF $200 \mu \mathrm{g} O D$} \\
\hline & & Week 12 & Week 24 & Week 12 & Week 24 & Week 12 & Week 24 \\
\hline \multirow[t]{5}{*}{ Overall } & $\mathrm{N}$ & 195 & 195 & 197 & 197 & 194 & 194 \\
\hline & $\mathrm{n}^{\dagger}$ & 190 & 190 & 187 & 187 & 186 & 186 \\
\hline & $\begin{array}{l}\text { LS mean change from } \\
\text { baseline (SE) }\end{array}$ & $0.178(0.0291)$ & $0.183(0.0300)$ & $0.364(0.0293)$ & $0.394(0.0302)$ & $0.209(0.0294)$ & $0.201(0.0303)$ \\
\hline & $\begin{array}{l}\text { Difference vs FP } \\
500 \mu \mathrm{g} \mathrm{BD}(95 \% \mathrm{Cl})\end{array}$ & - & - & $0.187(0.106-0.268)$ & $0.210^{*}(0.127-0.294)$ & $0.032(-0.050-0.113)$ & $0.018(-0.066-0.102)$ \\
\hline & $\begin{array}{l}\text { Difference vs FF } 200 \mu \mathrm{g} \\
\text { OD }(95 \% \text { Cl) }\end{array}$ & - & - & $0.155(0.074-0.237)$ & $0.193 *(0.108-0.277)$ & - & - \\
\hline \multirow[t]{3}{*}{$\operatorname{Japan}^{\ddagger}$} & $\mathrm{N}$ & 11 & 11 & 14 & 14 & 11 & 11 \\
\hline & $\mathrm{n}^{\dagger}$ & 10 & 10 & 13 & 13 & 11 & 11 \\
\hline & $\begin{array}{l}\text { LS mean change from } \\
\text { baseline (SE) }\end{array}$ & $0.136(0.1271)$ & $0.110(0.1310)$ & $0.399(0.1118)$ & $0.355(0.1152)$ & $0.097(0.1226)$ & $0.086(0.1263)$ \\
\hline \multirow{5}{*}{$\begin{array}{l}\text { Not- } \\
\text { Japan }\end{array}$} & $\mathrm{N}$ & 184 & 184 & 183 & 183 & 183 & 183 \\
\hline & $\mathrm{n}^{\dagger}$ & 180 & 180 & 174 & 174 & 175 & 175 \\
\hline & $\begin{array}{l}\text { LS mean change from } \\
\text { baseline (SE) }\end{array}$ & $0.183(0.0300)$ & $0.191(0.0309)$ & $0.361(0.0304)$ & $0.396(0.0313)$ & $0.214(0.0304)$ & $0.206(0.0314)$ \\
\hline & $\begin{array}{l}\text { Difference vs FP } 500 \mu \mathrm{g} \\
\text { BD }(95 \% \text { Cl) }\end{array}$ & - & - & $0.178(0.094-0.262)$ & $0.205(0.119-0.291)$ & $0.031(-0.053-0.115)$ & $0.015(-0.072-0.101)$ \\
\hline & $\begin{array}{l}\text { Difference vs FF } 200 \mu \mathrm{g} \\
\text { OD }(95 \% \mathrm{Cl})\end{array}$ & - & - & $0.147(0.062-0.231)$ & $0.190(0.103-0.277)$ & - & - \\
\hline
\end{tabular}

$B D$ twice daily, $C l$ confidence interval, $F E V_{1}$ forced expiratory volume in one second, $F F$ fluticasone furoate, $F P$ fluticasone propionate, $L S$ least-squares, $O D$ once daily, SE standard error, VI vilanterol

All values are in L. Analysis of covariance (ANCOVA) model using last observation carried forward. ${ }^{\dagger}$ Number of patients with analyzable data; ${ }^{\ddagger}$ Differences vs FP $500 \mu \mathrm{g} \mathrm{BD}$ and FF $200 \mu \mathrm{g} \mathrm{BD}$ are not presented for the Japan group due the low number of patients in this analysis; ${ }^{*} P \leq 0.001$ 


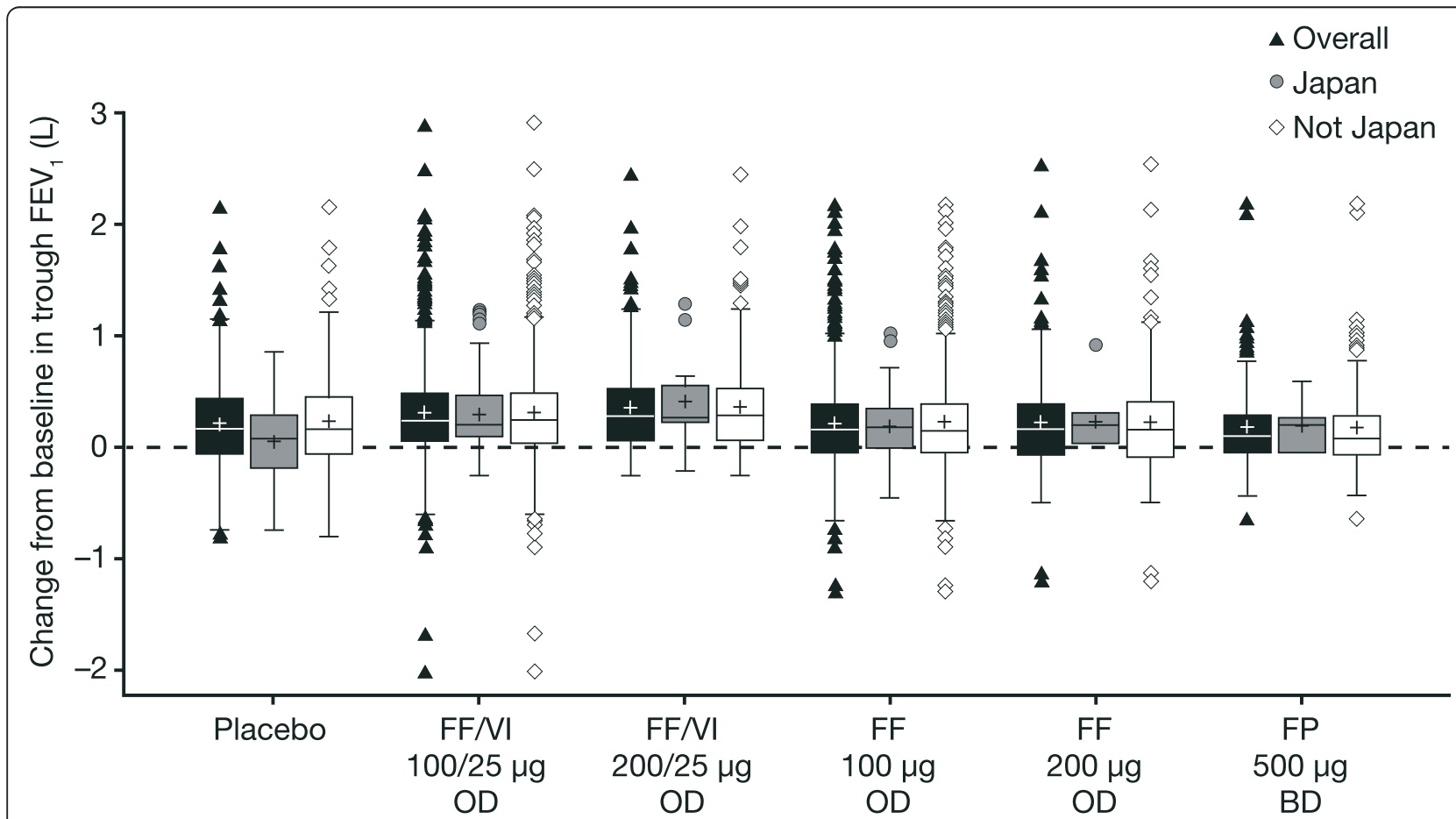

Fig. 1 Change from baseline in trough FEV ${ }_{1}$ at Week 12 (Efficacy population). Efficacy population consists of data from studies HZA106827, HZA106829, and HZA106837. Number of patients analyzed in a) Overall population: $N=193$ placebo, $N=1,201 \mathrm{FFNI} 100 / 25 \mu \mathrm{g} O \mathrm{D}, \mathrm{N}=187 \mathrm{FF} / \mathrm{II}$ 200/25 $\mu \mathrm{g}$ OD,

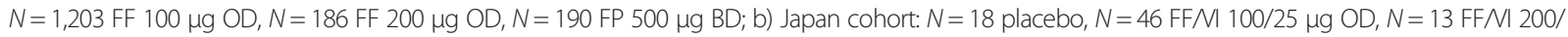

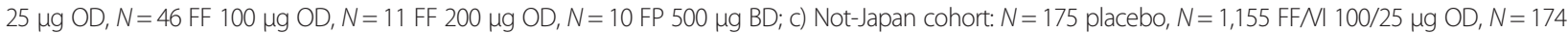
FFN 200/25 $\mu \mathrm{g} \mathrm{OD,} N=1,157 \mathrm{FF} 100 \mu \mathrm{g}$ OD, N=175 FF $200 \mu \mathrm{g}$ OD, N=180 FP $500 \mu \mathrm{g}$ BD. The limits of the box represent the interquartile range (IQR) from the 25th to 75th percentiles, respectively, for the lower and upper limits of the box; error bars represent the minimum and maximum values within $1.5 \times$ IQR below and above the 25th and 75th percentiles, respectively; the horizontal line within the box represents the median; + represents the mean; symbols represent data that are either $<1.5 \times 1 \mathrm{QQR}$ below the 25 th percentile or $>1.5 \times 1 \mathrm{QR}$ above the 75 th percentile. BD twice daily, FEV ${ }_{1}$ forced expiratory volume in one second, FF fluticasone furoate, FP fluticasone propionate, OD once daily, VI vilanterol

with FF/VI 100/25 $\mu \mathrm{g}$, FF/VI 200/25 $\mu \mathrm{g}$, and placebo in Japan + Korea was 3 (6\%), 1 (7\%), and 0 patients, respectively, and for Not-Japan + Korea was $14(1 \%)$, $6(3 \%)$, and $1(<1 \%)$, respectively.

Exposure to treatment varied across treatment arms as a consequence of the different durations of the studies integrated (Additional File 7) and should be considered when interpreting the incidence of AEs in each treatment group. For example, in both Japan + Korea and Not-Japan + Korea patients, there was a $>5$-fold longer mean duration of exposure in the FF/VI 100/25 $\mu \mathrm{g}$ treatment group relative to the placebo group.

On-treatment AEs (Table 4) were reported by a greater proportion of Japan + Korea patients (placebo: 41 \%; FF/VI: 64-79 \%; FF: 69-73 \%) than Not-Japan + Korea patients (placebo: 23 \%; FF/VI: 45-57 \%; FF: 36-54 \%). The most frequently reported on-treatment AEs in all populations were nasopharyngitis, headache, bronchitis, and upper respiratory tract infections (Additional File 8). A greater proportion of Japan + Korea patients reported nasopharyngitis (placebo: $21 \%$; FF/VI: 49-50 \%; FF: 23-29 \%) than
Not-Japan + Korea patients (placebo: 5 \%; FF/VI: 10-13 \%; FF: 8-10 \%). A lower proportion of Japan + Korea patients reported headache (placebo: $3 \%$; FF/VI: 0-6 \%; FF: 7-9 \%) than Not-Japan + Korea patients (placebo: $6 \%$; FF/VI: 6-17 \%; FF: 7-15\%). For the pooled dataset, the incidences of AEs deemed to be treatment related by the investigator, as well as fatal SAEs and non-fatal SAEs, were all low and generally reported for similar proportions of patients recruited from Japan + Korea and Not-Japan + Korea, with no trends across active treatment arms (Table 4). The most commonly reported treatment-related AEs in Japan + Korea were the well described local ICS effects of candidiasis and dysphonia, which were also among the most common treatment-related AEs in the Not-Japan + Korea cohort. For other potential class-related effects, the incidence of AEs related to blood glucose or potassium was low in the patients recruited from Japan + Korea and NotJapan + Korea. Changes in heart rate $\geq 6 \mathrm{bpm}$ relative to placebo were uncommon. Changes from baseline in the maximum post-baseline QTcF were consistent across all 
Table 4 Incidence of on-treatment AEs by treatment group and patient cohort (Safety population)

\begin{tabular}{|c|c|c|c|c|c|}
\hline & \multicolumn{5}{|c|}{ Incidence of AEs, n/N (\%) } \\
\hline & Placebo & FF/NI 100/25 $\mu \mathrm{g} \mathrm{OD}$ & FF/NI 200/25 $\mu \mathrm{g}$ OD & $\mathrm{FF} 100 \mu \mathrm{g}$ OD & FF $200 \mu \mathrm{g} \mathrm{OD}$ \\
\hline Range of treatment duration of studies integrated (weeks) & $8-12$ & $12-76$ & 24 & $8-76$ & $8-24$ \\
\hline \multicolumn{6}{|l|}{ On-treatment All AEs } \\
\hline Japan + Korea & $12 / 29(41)$ & $37 / 47(79)^{*}$ & $9 / 14(64)^{*}$ & $38 / 55(69)$ & $16 / 22(73)$ \\
\hline Not-Japan + Korea & $87 / 375(23)$ & $658 / 1,163(57)$ & $83 / 183(45)$ & $744 / 1,375(54)$ & $134 / 368(36)$ \\
\hline Overall & $99 / 404(25)$ & $695 / 1,210(57)$ & $92 / 197(47)$ & $782 / 1,430(55)$ & 150/390 (38) \\
\hline \multicolumn{6}{|l|}{ On-treatment Drug-Related AEs } \\
\hline Japan + Korea & $0 / 29(0)$ & $4 / 47(9)^{*}$ & $3 / 14(21)^{*}$ & $1 / 55(2)$ & $2 / 22(9)$ \\
\hline Not-Japan + Korea & $6 / 375(2)$ & $79 / 1,163(7)$ & 14/183 (8) & $90 / 1,375(7)$ & $17 / 368(5)$ \\
\hline Overall & $6 / 404(1)$ & $83 / 1,210(7)$ & 17/197 (9) & $91 / 1,430(6)$ & 19/390 (5) \\
\hline \multicolumn{6}{|l|}{$\begin{array}{l}\text { On-treatment AEs Leading to Permanent Discontinuation } \\
\text { of Investigative Product or Withdrawal from the Study }\end{array}$} \\
\hline Japan + Korea & $0 / 29(0)$ & $3 / 47(6)^{*}$ & $1 / 14(7)^{*}$ & 2/55 (4) & $1 / 22(5)$ \\
\hline Not-Japan + Korea & $1 / 375(<1)$ & 15/1,163 (1) & 6/183 (3) & $21 / 1,375(2)$ & $4 / 368(1)$ \\
\hline Overall & $1 / 404(<1)$ & $18 / 1,210(1)$ & 7/197 (4) & $23 / 1,430(2)$ & $5 / 390(1)$ \\
\hline \multicolumn{6}{|l|}{ On-treatment Non-fatal Serious AEs } \\
\hline Japan + Korea & $0 / 29(0)$ & $1 / 47(2)^{*}$ & $0 / 14(0)^{*}$ & $1 / 55(2)$ & $0 / 22(0)$ \\
\hline Not-Japan + Korea & $0 / 375(0)$ & $39 / 1,163(3)$ & 6/183 (3) & $29 / 1,375(2)$ & $1 / 368(<1)$ \\
\hline Overall & 0/404 (0) & $40 / 1,210(3)$ & 6/197 (3) & $30 / 1,430(2)$ & $1 / 390(<1)$ \\
\hline \multicolumn{6}{|l|}{ On-treatment Fatal AEs } \\
\hline Japan + Korea & $0 / 29(0)$ & $0 / 47(0)^{*}$ & $0 / 14(0)^{*}$ & $0 / 55(0)$ & $0 / 22(0)$ \\
\hline Not-Japan + Korea & $0 / 375(0)$ & $1 / 1,163(<1)$ & 0/183 (0) & $1 / 1,375(<1)$ & $0 / 368(0)$ \\
\hline Overall & 0/404 (0) & $1 / 1,210^{\dagger}(<1)$ & 0/197 (0) & $1 / 1,430(<1)$ & 0/390 (0) \\
\hline
\end{tabular}

$A E$ adverse event, $F F$ fluticasone furoate, $O D$ once daily, $V I$ vilanterol

Safety population consists of data from studies HZA106827, HZA106829, HZA106837, FFA109685, and FFA109687. * Only patients recruited from Japan; ${ }^{\dagger}$ One additional patient (South East Asian) died during follow-up (91 days after withdrawal)

treatment arms, including placebo, in the Japan + Korea and Not-Japan + Korea patients. The incidence of ECG abnormalities of potential clinical importance did not increase for any post-dose assessment relative to pre-dose assessments for any treatment arm in any population.

There were two SAEs (both subarachnoid hemorrhage) in Japan + Korea patients (FF/VI 100/25 $\mu \mathrm{g} N=1$; FF $100 \mu \mathrm{g}=1$ ), which were not considered treatment related. In the Overall population, the most frequent SAE was asthma exacerbation (FF/VI 100/25 $\mu \mathrm{g} N=11$; FF $100 \mu \mathrm{g} N=9$; FF $200 \mu \mathrm{g} N=1$ ). For the Asthma Composite Endpoint, no events (asthma-related hospitalizations, intubations, and deaths) were reported for patients recruited from Japan + Korea, and the incidence was $<1 \%$ in each treatment arm in Not-Japan + Korea patients. The incidence of respiratory-related SAEs and pneumonia-related events was low in both the Japan + Korea and Not-Japan + Korea cohorts.

The urinary cortisol population comprised 1,385 patients (88 [6\%] recruited from Japan + Korea). Geometric mean ratios of $24 \mathrm{~h}$ urinary cortisol excretion at the end of treatment relative to baseline were generally close to one (Fig. 2). Treatment comparisons for the Japan + Korea and Not-Japan + Korea cohorts were performed for FF/VI 100/25 $\mu \mathrm{g}$ versus FF $100 \mu \mathrm{g}$, FF/VI 200/25 $\mu$ g versus FF $200 \mu \mathrm{g}$, and FF $100 \mu \mathrm{g}$ or FF $200 \mu \mathrm{g}$ versus placebo, and were not statistically significant (the $95 \%$ confidence intervals encompassed one; Table 5). In the Overall population, only FF $200 \mu \mathrm{g}$ versus placebo was associated with statistically lower cortisol ratios (16\% reduction in urine cortisol excretion [ratio of end of treatment to baseline]), which is unlikely to be clinically relevant (Table 5). No statistically significant differences in the treatment comparisons were observed between the Japan + Korea and the Not-Japan + Korea cohorts (Additional File 9).

\section{Discussion}

The ethnic sensitivity of the novel OD treatment FF/VI in East Asian asthma patients included in Phase IIb and Phase III clinical studies has been assessed in this analysis. The efficacy (trough $\mathrm{FEV}_{1}$ ) results in asthma patients in Japan and the safety profile observed in asthma patients in 


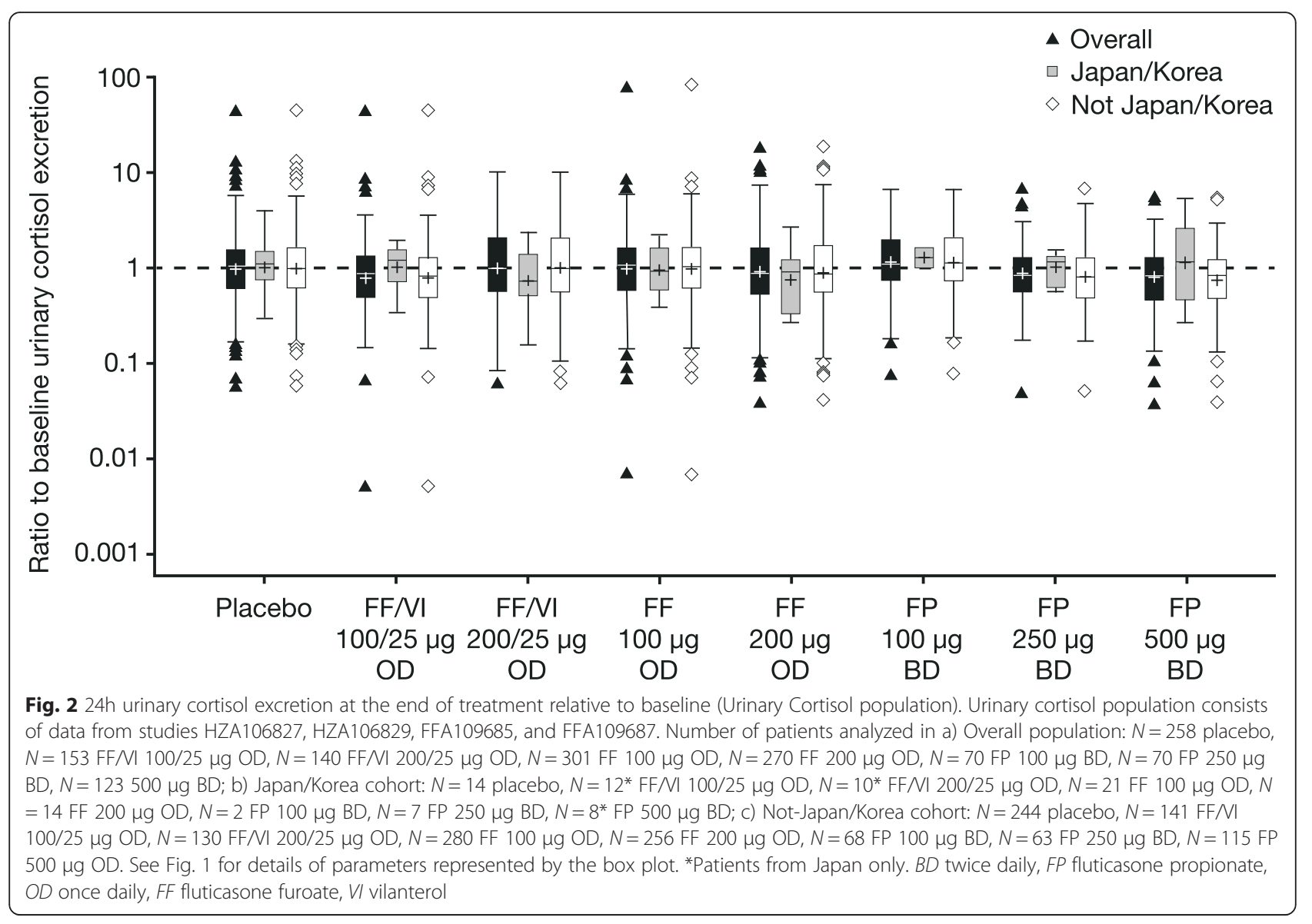

Japan + Korea did not indicate that a different clinical dose of $\mathrm{FF} / \mathrm{VI}$ is required in East Asian asthma patients, relative to non-East Asian patients.

In both the Japan and Not-Japan cohorts, a notably higher proportion of patients receiving placebo withdrew due to lack of efficacy, relative to patients receiving FF/VI. The improvements in trough $\mathrm{FEV}_{1}$ at Week 12 show that asthma patients in Japan benefited from FF/VI 100/25 $\mu \mathrm{g}$ or FF/VI 200/25 $\mu \mathrm{g}$, and that response to treatment in Japanese patients is similar to that seen in the global population, suggesting the doses used in the global population are appropriate for use in Japanese patients. Patients recruited from Japan had a lower placebo response than patients from Not-Japan, resulting in the observation of greater numerical improvements with $\mathrm{FF} / \mathrm{VI}$ versus placebo in the Japan cohort. For the FF/VI 100/25 $\mu$ g versus FF $100 \mu \mathrm{g}$ treatment comparison, differences between populations were less pronounced. The results for FF/VI 200/25 $\mu \mathrm{g}$ OD versus FP $500 \mu \mathrm{g}$ BD at Week 12 and Week 24 also demonstrate that the change from baseline data for trough $\mathrm{FEV}_{1}$ appeared to be similar between the Japan and Not-Japan asthma patients.

There was a trend towards a greater proportion of patients in Japan + Korea reporting on-treatment AEs with FF/VI or FF than in the Not-Japan + Korea cohort. This trend was also observed with placebo, which indicates that patients in Japan + Korea had a higher tendency to report AEs in general. Regional differences in AE reporting have been observed for other drugs [21]. Furthermore, there was no evidence of ethnic differences for treatment-related AEs or class-related AEs. There were no deaths or treatmentrelated SAEs in patients recruited from Japan + Korea. The slightly greater proportion of withdrawals due to AEs in the Japan + Korea versus Not-Japan + Korea patients should be interpreted with caution due to low patient numbers; generally, withdrawals due to AEs were low and there was no clear indication of an ethnic difference. The safety profile of FF/VI in this analysis is consistent with that reported previously for Japanese asthma patients from a 12-month safety study of FF/VI [22], as well as in non-Japanese asthma patients in other multiregional studies [23, 24].

Systemic exposure to high-dose ICS has been associated with unwanted changes in hypothalamic-pituitaryadrenal (HPA) axis function and cortisol suppression [25]. Previous studies in Japanese subjects [26, 27] and other multiregional studies $[25,28]$ have assessed the 
Table 5 Treatment comparison of $24 \mathrm{~h}$ urinary cortisol excretion at end of treatment ( $\mathrm{nmol} / 24 \mathrm{~h}$ ) (Urinary Cortisol population)

\begin{tabular}{|c|c|c|c|c|c|c|}
\hline & & Placebo & FF/VI 100/25 $\mu \mathrm{g}$ OD & FF/VI 200/25 $\mu \mathrm{g}$ OD & $\mathrm{FF} 100 \mu \mathrm{g} O D$ & FF $200 \mu \mathrm{g}$ OD \\
\hline \multirow[t]{7}{*}{ Overall } & N & 258 & 153 & 140 & 301 & 270 \\
\hline & $\mathrm{n}^{\dagger}$ & 258 & 153 & 140 & 301 & 270 \\
\hline & LS geometric mean & 64.29 & 56.01 & 56.90 & 61.43 & 54.10 \\
\hline & LS ratio to baseline & 1.03 & 0.9 & 0.91 & 0.99 & 0.87 \\
\hline & Ratio to placebo (95 \% Cl) & - & - & - & $0.96(0.85-1.08)$ & $0.84(0.71-0.99)^{*}$ \\
\hline & Ratio to FF $100 \mu \mathrm{g}(95 \% \mathrm{Cl})$ & - & $0.91(0.78-1.06)$ & - & - & - \\
\hline & Ratio to FF $200 \mu \mathrm{g}(95 \%$ Cl) & - & - & $1.05(0.88-1.26)$ & - & - \\
\hline \multirow[t]{7}{*}{ Japan + Korea } & $\mathrm{N}$ & 14 & 12 & 10 & 21 & 14 \\
\hline & $\mathrm{n}^{\dagger}$ & 14 & 12 & 10 & 21 & 14 \\
\hline & LS geometric mean & 71.40 & 68.27 & 47.52 & 66.13 & 49.20 \\
\hline & LS ratio to baseline & 1.15 & 1.10 & 0.76 & 1.06 & 0.79 \\
\hline & Ratio to placebo (95 \% Cl) & - & - & - & $0.93(0.56-1.52)$ & $0.69(0.40-1.20)$ \\
\hline & Ratio to FF $100 \mu \mathrm{g}(95 \% \mathrm{Cl})$ & - & $1.03(0.61-1.74)$ & - & - & - \\
\hline & Ratio to FF $200 \mu \mathrm{g}(95 \% \mathrm{Cl})$ & - & - & $0.97(0.53-1.78)$ & - & - \\
\hline \multirow[t]{7}{*}{ Not-Japan + Korea } & N & 244 & 141 & 130 & 280 & 256 \\
\hline & $\mathrm{n}^{\dagger}$ & 244 & 141 & 130 & 280 & 256 \\
\hline & LS geometric mean & 63.73 & 55.11 & 58.00 & 61.09 & 54.34 \\
\hline & LS ratio to baseline & 1.02 & 0.89 & 0.93 & 0.98 & 0.87 \\
\hline & Ratio to placebo $(95 \% \mathrm{Cl})$ & - & - & - & $0.96(0.84-1.09)$ & $0.85(0.72-1.01)$ \\
\hline & Ratio to FF $100 \mu \mathrm{g}(95 \% \mathrm{Cl})$ & - & $0.90(0.77-1.06)$ & - & - & - \\
\hline & Ratio to FF $200 \mu \mathrm{g}(95 \%$ Cl) & - & - & $1.07(0.89-1.28)$ & - & - \\
\hline
\end{tabular}

Cl confidence interval, FF fluticasone furoate, $L S$ least-squares, $O D$ once daily, VI vilanterol

Data from studies FFA109685, FFA109687, HZA106827, and HZA106829. Analysis performed using ANCOVA with covariates of study, gender, age, treatment group, geographical region, geographical region-by-treatment interaction (Japan + Korea and Not-Japan + Korea analysis only), and the log of baseline values. ${ }^{\dagger}$ Number of patients with analyzable data at end of treatment; ${ }^{*} P=0.038$; Overall FF $200 \mu \mathrm{g} v$ s placebo

dose-dependent effect of inhaled FF (doses up to $4,000 \mu \mathrm{g}$ administered as a single dose, including $800 \mu \mathrm{g}$ $\mathrm{OD}$ in Japanese) on urine or plasma cortisol. In the current pooled analysis for the treatment comparison of urine cortisol effect (FF versus placebo, or FF/VI versus dose-matched FF), no statistically significant differences were observed between the Japan + Korea and the NotJapan + Korea populations. In the Overall population of the current pooled safety analysis, the FF $200 \mu \mathrm{g}$ treatment arm demonstrated a $16 \%$ reduction in urine cortisol excretion (ratio of end of treatment to baseline) relative to placebo, which was statistically significant but unlikely to be clinically relevant. However, modeling of the plasma FF concentration effect on urine or serum cortisol in multinational populations [25] and in healthy Japanese subjects [26] has demonstrated that clinical doses of FF $(\leq 200 \mu \mathrm{g})$ have not been associated with decreases in cortisol of clinical concern. In addition, the definitive study of the effect of FF/VI 100/25 $\mu \mathrm{g}$ and 200/25 $\mu \mathrm{g}$ on the HPA axis, in which 24-h serum cortisol was assessed in patients with asthma, did not show a significant reduction of cortisol levels relative to placebo with either strength of FF/VI [28].
The absence of treatment-related changes of concern in blood glucose or potassium concentrations for VI administered as FF/VI are consistent with previous reports $[26,29,30]$ in healthy Western and Japanese subjects. In the current analysis, there was no indication that VI administered as FF/VI was related to ECG abnormalities, consistent with previous reports in healthy Japanese subjects [26] and a multiregional study [29], suggesting that the clinical dose of VI $25 \mu \mathrm{g}$ does not have a clinically relevant impact on QT/QTc interval. Increases in heart rate are a known LABA effect [31] and the small increases from baseline in heart rate observed in the current analysis are consistent with the small, transient effects reported in other clinical studies with inhaled VI [23, 32].

The pharmacokinetics of FF and VI have been characterized during the FF/VI development program in healthy subjects, including East Asians [26], as well as in patients with asthma or COPD [33]. In healthy subjects, higher FF systemic exposure ( $<2$-fold) following oral inhalation has been observed in East Asians than Caucasians [27], which may be related to differences in absorption from the lung [27]. However, as previously 
described, clinical doses of FF $(\leq 200 \mu \mathrm{g})$ have not been associated with urine cortisol suppression of clinical concern in Japanese healthy subjects and asthma patients. Therefore, the modest increase in FF systemic exposure anticipated in East Asian asthma patients does not result in clinically significant effects on HPA axis function. As previously noted, effects potentially associated with systemic VI concentrations (effects on glucose, potassium, and cardiovascular effects) were limited and were not of clinical concern in Japan + Korea and Not-Japan + Korea patients with asthma.

The current analysis has some limitations. Only a limited total number of patients in Japan and Korea were included in these multiregional clinical studies and the Japan and Japan + Korea cohorts were not formally powered for statistical analysis. Furthermore, even though these were pre-specified, a number of subgroup analyses were performed and multiplicity issues should be considered when drawing inference from the results of these analyses. It is also important to consider the differences in duration of exposure to study drug across the five studies, in particular, the markedly lower number of patient-years of exposure to placebo that limits the ability to directly compare safety data. In addition, differences in study design restrict the treatment arms that could be pooled for statistical comparisons of efficacy data, preventing the statistical comparison of FF/VI 200/ $25 \mu \mathrm{g}$ versus placebo.

\section{Conclusion}

The totality of the data from the current analysis, taken together with previously published results in Japanese asthma patients and Japanese healthy subjects [22, 26, 27], provide confidence that the efficacy and safety of FF/VI is of low ethnic sensitivity and this supports the conclusion that the same clinical doses of FF/VI $(100 / 25 \mu \mathrm{g}$ OD and 200/25 $\mu \mathrm{g}$ OD) are appropriate for both East Asian and non-East Asian asthma patients.

\section{Availability of data}

Further details of each of the 5 studies included in this analysis, and a summary of the efficacy and safety results obtained for each study, are provided in the Clinicaltrials.gov registry (https://clinicaltrials.gov) and the GlaxoSmithKline Clinical Study Register:

HZA106827 - http://www.gsk-clinicalstudyregister.com/study/106827\#ps

HZA106829 - https://clinicaltrials.gov/ct2/show/

NCT01134042?term=HZA106829\&rank=1

HZA106837 - https://clinicaltrials.gov/ct2/show/

NCT01086384?term $=106837 \&$ rank $=1$

FFA109685 - https://clinicaltrials.gov/ct2/show/

NCT00603278?term $=$ FFA109685\&rank $=1$

FFA109687 - https://clinicaltrials.gov/ct2/show/ NCT00603382?term=FFA109687\&rank=1
The studies are also fully published in peer-reviewed journals (Bleecker et al. J Allergy Clin Immunol Pract. 2014;2:553-61. O'Byrne et al. Eur Respir J. 2014;43:773-82. Bateman et al. Thorax. 2014;69:312-9. Bleecker et al. Ann Allergy Asthma Immunol. 2012;109:353-8. Bateman et al. Respir Med. 2012;106:642-50).

\section{Additional files}

Additional file 1: Profile of the three Phase III studies included in both the efficacy and safety analyses. (DOCX 47.4 KB)

Additional file 2: Profile of the two additional Phase Ilb studies included in only the safety analyses. (DOCX $25.6 \mathrm{~KB}$ )

Additional file 3: List of Institutions and Independent Ethics Committees/Institutional Review Boards for Studies HZA106829, HZA106827, HZA106837, FFA109685, FFA109687 Study HZA106829: 63 Centres. (DOCX $100 \mathrm{~KB}$ )

Additional file 4: Adjusted treatment differences from baseline in trough FEV1 at Week 12 (Efficacy population). (DOCX 1.49 MB)

Additional file 5: Ease of use of the ELLIPTA ${ }^{\circledR}$ dry powder inhaler (DPI; ELLIPTA $^{\oplus}$ is a trademark of the GlaxoSmithKline group of companies). (DOCX $22.5 \mathrm{~KB}$ )

Additional file 6: Summary of ease of use assessment and responses to questions on the ELLIPTA DPI by patients from Japan (HZA106827 ITT population). (DOCX $25.2 \mathrm{~KB}$ )

Additional file 7: Summary of exposure in each treatment arm (Safety population). (DOCX $26.5 \mathrm{~KB}$ )

Additional file 8: AEs reported by $\geq 3$ patients in the Japan+Korea cohort of any relevant treatment arm and the corresponding incidence in the Not-Japan+Korea cohort and the Overall population (Safety population). (DOCX 26.9 KB)

Additional file 9: Region ratios of 'treatment effect' in Japan+Korea and Not-Japan+Korea patients, where 'treatment effect' is the comparison between treatment arms of $24 \mathrm{~h}$ urinary cortisol excretion ratio (end of treatment/baseline; Urinary Cortisol population). (DOCX 944 KB)

\section{Abbreviations}

AE: Adverse event; ANCOVA: Analysis of covariance; BD: Twice daily; $\mathrm{Cl}$ : Confidence interval; DPI: Dry powder inhaler; ECG: Electrocardiogram; $\mathrm{FEV}_{1}$ : Forced expiratory volume in one second; FF: Fluticasone furoate; FP: Fluticasone propionate; HPA: Hypothalamic-pituitary-adrenal; ICS: Inhaled corticosteroid; ITT: Intent-to-treat; LABA: Long-acting $\beta_{2}$-agonist; LS: Leastsquares; min: Minimum; max: Maximum; OD: Once daily; QTcF: QT corrected using Frederica's correction; SAE: Serious adverse event; SD: Standard deviation; SE: Standard error; VI: Vilanterol.

\section{Competing interests}

This analysis was funded by GSK, and the studies included in the analysis were sponsored by GSK (GSK study numbers HZA106827 [Clinicaltrials.gov registration number: NCT01165138, registered on July 15 2010]; HZA106829 [NCT01134042, May 27, 2010]; HZA106837 [NCT01086384, March 11, 2010]; FFA109685 [NCT00603278, December 27, 2007]; and FFA109687 [NCT00603382, December 27, 2007]).

ASG, CG, MHJ, CSC and LJ are employed by and are shareholders in GSK. YS is employed by GSK. SH has, within the previous 3 years, received honoraria for lectures from Abbott Japan, Astellas Pharma, AstraZeneca, Boehringer Ingelheim, Eisai, GSK, Kyorin Pharmaceutical, Merck, Sharp \& Dohme, Novartis Pharma, and Teijin Pharma.

\section{Authors' contributions}

ASG, CG, MHJ, CSC and LJ contributed to the conception and design of this study; CG, SH and YS contributed to the data analysis; and ASG, CG, SH, MHJ, CSC, YS and $L$ contributed to the interpretation of the results. All authors were involved in drafting the manuscript, or revising it critically, and have given approval for publication of the final version. 


\section{Acknowledgements}

The authors would like to acknowledge Dr Romina Nand (GSK) and Dr Carol Lee (GSK) for their contributions to the ethnic sensitivity assessment. Editorial support in the form of development of the draft outline in consultation with the authors was provided by David Cutler, PhD at Gardiner-Caldwell Communications (Macclesfield, UK), while development of the manuscript first and second drafts in consultation with the authors, editorial suggestions to draft versions of this paper, assembling tables and figures, collating author comments, copyediting, fact checking, referencing, and graphic services was provided by Laura Maguire, MChem at Gardiner-Caldwell Communications (Macclesfield, UK). Editorial support was funded by GSK.

\section{Author details}

'Clinical Pharmacology Modelling \& Simulation, GSK R\&D, 82 Hughes Ave, Ermington, Sydney NSW 2115, Australia. ${ }^{2}$ Quantitative Sciences Division, GSK, Uxbridge, UK. ${ }^{3}$ Hiroshima Allergy and Respiratory Clinic, Hiroshima, Japan. ${ }^{4}$ Medical Affairs, GSK K.K., Tokyo, Japan. ${ }^{5}$ Medicines Development Respiratory, GSK K.K., Tokyo, Japan. ${ }^{6}$ Respiratory Medicines Discovery and Development, GSK, Uxbridge, UK.

Received: 29 June 2015 Accepted: 14 December 2015

Published online: 24 December 2015

\section{References}

1. Global Initiative for Asthma. Global Burden of Asthma. http://www.ginasthma. org/local/uploads/files/GINABurdenReport_1.pdf. Accessed 21 November 2014.

2. Ohta K, Yamaguchi M, Akiyama K, Adachi M, Ichinose M, Takahashi K, et al. Japanese guideline for adult asthma. Allergol Int. 2011;60:115-45.

3. Global Initiative for Asthma. Global strategy for asthma management and prevention. Updated August 2014. http://www.ginasthma.org/local/uploads/ files/GINA_Report_2014_Aug12_1.pdf. Accessed 21 December 2015.

4. Bleecker ER, Lötvall J, O'Byrne PM, Woodcock A, Busse WW, Kerwin EM, et al. Fluticasone furoate-vilanterol $100-25 \mathrm{mcg}$ compared with fluticasone furoate $100 \mathrm{mcg}$ in asthma: a randomized trial. J Allergy Clin Immunol Pract. 2014:2:553-61.

5. O'Byrne PM, Bleecker ER, Bateman ED, Busse WW, Woodcock A, Forth R, et al. Once-daily fluticasone furoate alone or combined with vilanterol in persistent asthma. Eur Respir J. 2014;43:773-82.

6. Cochrane GM. Compliance and outcomes in patients with asthma. Drugs. 1996;52 Suppl 6:12-9.

7. Guest JF, Davie AM, Ruiz FJ, Greener MJ. Switching asthma patients to a once-daily inhaled steroid improves compliance and reduces healthcare costs. Prim Care Respir J. 2005;14:88-98.

8. Mäkelä MJ, Backer V, Hedegaard M, Larsson K. Adherence to inhaled therapies, health outcomes and costs in patients with asthma and COPD. Respir Med. 2013;107:1481-90.

9. Bjornsson TD, Wagner JA, Donahue SR, Harper D, Karim A, Khouri MS, et al. A review and assessment of potential sources of ethnic differences in drug responsiveness. J Clin Pharmacol. 2003;43:943-67.

10. Huang SM, Temple R. Is this the drug or dose for you? Impact and consideration of ethnic factors in global drug development, regulatory review, and clinical practice. Clin Pharmacol Ther. 2008;84:287-94.

11. National Institutes of Health (NIH). Guidelines for the Diagnosis and Management of Asthma - Expert Panel Report 3 2007. U.S. Department of Health and Human Services, Bethesda, MD; 2007. http://www.nhlbi.nih.gov/ guidelines/asthma/asthgdln.pdf.

12. WMA Declaration of Helsinki - Ethical Principles for Medical Research Involving Human Subjects. Adopted by the 18th WMA General Assembly, Helsinki, Finland, June 1964 and amended (latest) by the 59th WMA General Assembly, Seoul, Korea, October 2008. http://www.wma.net/en/ 30publications/10policies/b3/index.html. Accessed 14 June 2013.

13. Bateman ED, O'Byrne PM, Busse WW, Lötvall J, Bleecker ER, Andersen L, et al. Once-daily fluticasone furoate (FF)/vilanterol reduces risk of severe exacerbations in asthma versus FF alone. Thorax. 2014;69:312-9.

14. Bleecker ER, Bateman ED, Busse WW, Woodcock A, Frith L, House KW, et al. Once-daily fluticasone furoate is efficacious in patients with symptomatic asthma on low-dose inhaled corticosteroids. Ann Allergy Asthma Immunol. 2012;109:353-8

15. Bateman ED, Bleecker ER, Lötvall J, Woodcock A, Forth R, Medley H, et al. Dose effect of once-daily fluticasone furoate in persistent asthma: a randomized trial. Respir Med. 2012;106:642-50.
16. Jin HJ, Tyler-Smith C, Kim W. The peopling of Korea revealed by analysis of mitochondrial DNA and Y-chromosomal markers. PLoS ONE. 2009;4, e4210.

17. HUGO Pan-Asian SNP Consortium, Abdulla MA, Ahmed I, Assawamakin A, Bhak J, Brahmachari SK, et al. Mapping human genetic diversity in Asia. Science. 2009;326:1541-5.

18. Chowbay B, Zhou S, Lee EJ. An interethnic comparison of polymorphisms of the genes encoding drug-metabolizing enzymes and drug transporters: experience in Singapore. Drug Metab Rev. 2005;37:327-78.

19. Quanjer PH, Tammeling GJ, Cotes JE, Pedersen OF, Peslin R, Yernault JC. Lung volumes and forced ventilatory flows. Report working party standardization of lung function tests, european community for steel and coal. Official statement of the european respiratory society. Eur Respir J Suppl. 1993;16:5-40.

20. Cotes JE, Leathart GL. Lung function: assessment and application in medicine. 5th ed. Oxford: Blackwell Scientific Publications; 1993.

21. Kanmuri K, Narukawa M. Investigation of the safety profiles of Japanese clinical trials. Ther Innov Reg Sci. 2014;48:308-15.

22. Muraki M, Soutome T, Hashimoto K, Tohda Y. Long-term study of fluticasone furoate/vilanterol combination (FFNI) and FF alone in Japanese adult patients with bronchial asthma. Allergol Immunol. 2013;20:110-25.

23. Busse WW, O'Byrne PM, Bleecker ER, Lötvall J, Woodcock A, Andersen L, et al. Safety and tolerability of the novel inhaled corticosteroid fluticasone furoate in combination with the $\beta 2$ agonist vilanterol administered once daily for 52 weeks in patients $\geq 12$ years old with asthma: a randomised trial. Thorax. 2013:68:513-20.

24. Woodcock A, Bleecker ER, Lötvall J, O'Byrne PM, Bateman ED, Medley H, et al. Efficacy and safety of fluticasone furoate/vilanterol compared with fluticasone propionate/salmeterol combination in adult and adolescent patients with persistent asthma: a randomized trial. Chest. 2013;144:1222-9.

25. Allen $\mathrm{A}$. The relationship between fluticasone furoate systemic exposure and cortisol suppression. Clin Pharmacokinetics. 2013;52:885-96.

26. Nakahara N, Wakamatsu A, Kempsford R, Allen A, Yamada M, Nohda S, et al. The safety, pharmacokinetics and pharmacodynamics of a combination of fluticasone furoate and vilanterol in healthy Japanese subjects. Int J Clin Pharmacol Ther. 2013;51:660-71.

27. Allen A, Bal J, Cheesbrough A, Hamilton M, Kempsford R. Pharmacokinetics and pharmacodynamics of intravenous and inhaled fluticasone furoate in healthy Caucasian and East Asian subjects. Br J Clin Pharmacol. 2014;77:808-20.

28. Allen A, Schenkenberger I, Trivedi R, Cole J, Hicks W, Gul N, et al. Inhaled fluticasone furoate/vilanterol does not affect hypothalamic-pituitary-adrenal axis function in adolescent and adult asthma: randomised, double-blind, placebo-controlled study. Clin Respir J. 2013;7:397-406.

29. Lötvall J, Bateman ED, Bleecker ER, Busse WW, Woodcock A, Follows R, et al. $24 \mathrm{~h}$ duration of the novel LABA vilanterol trifenatate in asthma patients treated with ICSs. Eur Respir J. 2012:40:570-9.

30. Mehta R, Preece A, Newlands A, Blowers J, Cahn A. Safety, pharmacodynamics (PD) and pharmacokinetics (PK) of darotropium (DARO) and vilanterol $(\mathrm{VI})$ in healthy subjects: two phase 1 studies. Eur Respir J. 2013:42(Suppl. 57):125-6s.

31. Cazzola M, Page CP, Rogliani P, Matera MG. $\beta 2$-agonist therapy in lung disease. Am J Respir Crit Care Med. 2013;187:690-6.

32. Kempsford R, Allen A, Kelly K, Saggu P, Crim C. A repeat-dose thorough QT study of inhaled fluticasone furoate (FF)/vilanterol (VI) combination in healthy subjects. Br J Clin Pharmacol. 2014;77:466-79.

33. Relvar Ellipta: EPAR - Product Information. 10 December 2013; updated 13 August 2014. http://www.ema.europa.eu/docs/en_GB/document_library/ EPAR_-_Product_Information/human/002673/WC500157633.pdf. Accessed 21 November 2014

34. Hankinson JL, Odencrantz JR, Fedan KB. Spirometric reference values from a sample of the general U.S. population. Am J Respir Crit Care Med. 1999;159: 179-87.

35. Hankinson JL, Kawut SM, Shahar E, Smith LJ, Stukovsky KH, Barr RG. Performance of American Thoracic Society-recommended spirometry reference values in a multiethnic sample of adults: the multi-ethnic study of atherosclerosis (MESA) lung study. Chest. 2010;137:138-45. 